\section{Endoscopic placement of a large-bore covered self- expandable metallic stent for cholangitis caused by mucus from a pancreatic mucinous neoplasm}

A 76-year-old woman, in whom an intraductal papillary mucinous neoplasm (IPMN) of the pancreas head had been diagnosed 28 months earlier, was admitted for the treatment of cholangitis; however, she refused surgical treatment. Upon progression, she had experienced recurrent cholangitis for 16 months caused by mucus within the bile duct, which was coming from an IPMN-linked fistula ( Fig. 1). To preserve bile flow, 10 -mm-diameter covered self-expandable metallic stents were placed endoscopically. However, the procedure had to be repeated five times in 8 months because the stents migrated distally or were clogged by mucus despite preventative measures, such as placement above the papilla of Vater, simultaneous placement of a covered self-expandable metallic stent and a double pigtail stent to prevent migration, partial stent-instent placement to connect the hilar biliary duct and the duodenum, and side-byside placement of two covered self-expandable metallic stents to occlude the fistula completely.

By the time of the sixth episode of cholangitis, large-bore covered self-expandable metallic stents, $20 \mathrm{~mm}$ in diameter and $80 \mathrm{~mm}$ in length (ComVi duodenal stent; membrane ( $\bullet$ Fig.4). las produce pancreatic outflow.

Endoscopy_UCTN_Code_TTT_1AR_2AZ

\section{Competing interests: None}

Taewoong Medical, Seoul, South Korea), had become commercially available in Japan. In a previous endoscopic procedure, mucus from another fistula, between the duodenal bulb and the IPMN, had been noted ( $\bullet$ Fig. 2 ); thus there was an alternative route for pancreatic outflow. Therefore, we attempted to control the cholangitis by blocking the fistula between the bile duct and the IPMN; a large-bore covered self-expandable metallic stent was successfully placed across the papilla ( Fig.3). After the procedure, pancreatitis was not noted, and the duration of stent patency was more than 6 months, as a result of the blocking effect of the covered

Generally, a long period of stent patency is not obtained following endoscopic treatment in such cases [ 1 -4]. However, largebore covered self-expandable metallic stents may improve patency, although their use is limited to cases in which fistu-

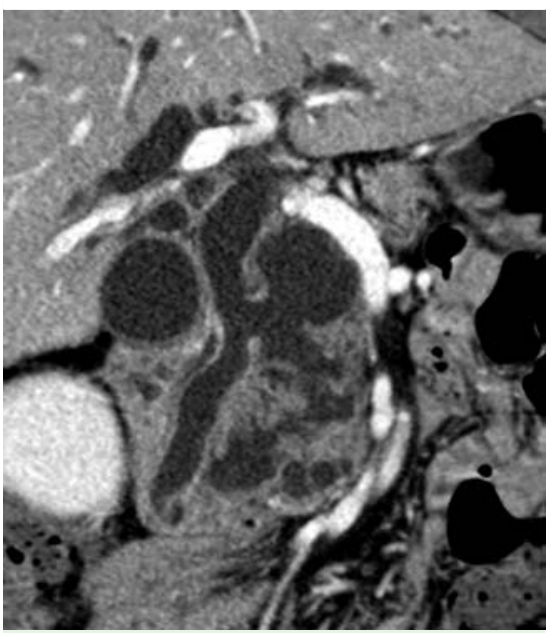

Fig. 1 Coronal contrast-enhanced computed tomographic scan reveals an intraductal papillary mucinous neoplasm in the pancreas head penetrating the bile duct and a fistula with a large diameter.

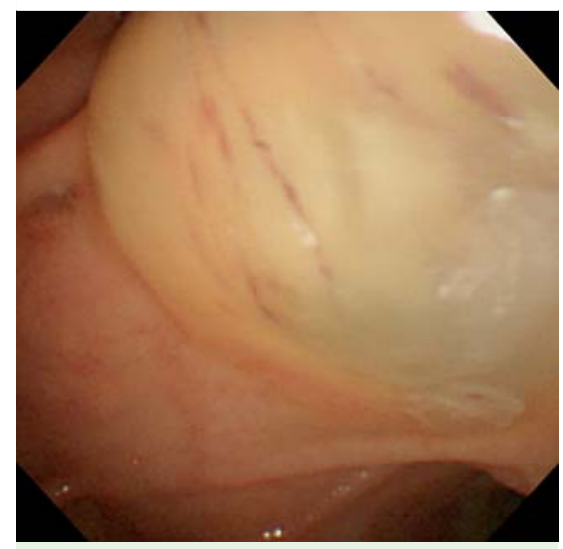

Fig. 2 Duodenoscopy during prior stent placement shows a large amount of mucus outflow from another fistula, between the duodenal bulb and the intraductal papillary mucinous neoplasm.
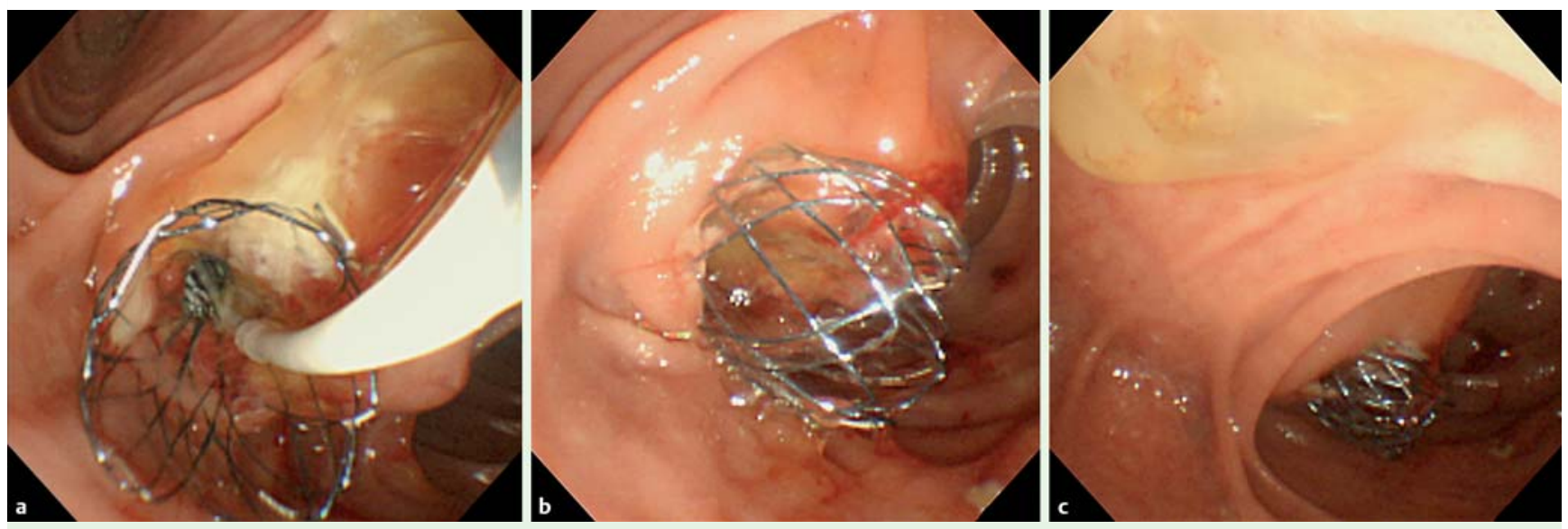

Fig.3 Transpapillary placement of a large-bore covered self-expandable metallic stent. a A large amount of mucus is squeezed out by expansion of stent. b The stent is placed across the papilla with approximately $10 \mathrm{~mm}$ of its distal end exposed to the duodenal lumen. $\mathbf{c}$ Another fistula is located about $3 \mathrm{~cm}$ proximal to the main papilla. 


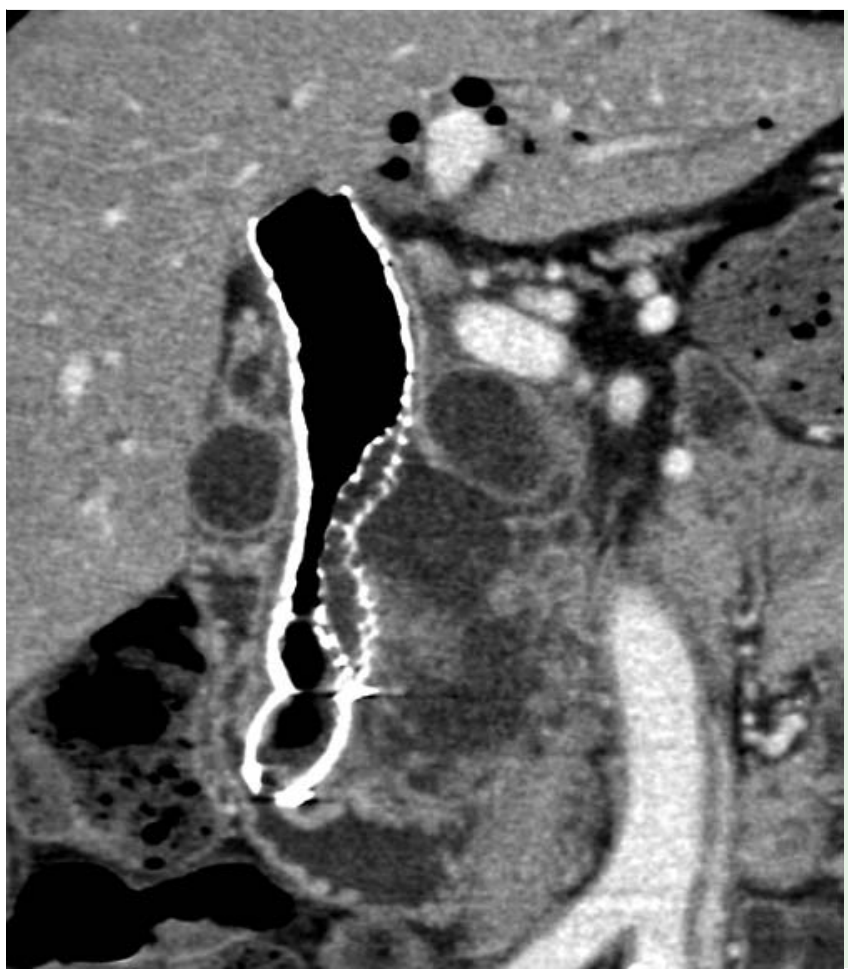

Fig. 4 Coronal contrast-enhanced computed tomographic scan 6 months after placement of a largebore covered self-expandable metallic stent shows the flow of mucus into the bile duct to be completely blocked; mucus was not observed within the large-bore covered self-expandable metallic stent, even though the stent was pushed inwards at the location of the fistula.

\section{Naotaka Hayasaka ${ }^{1,2}$, Tsuyoshi Hayashi', Michihiro Ono ${ }^{1}$, Hirotoshi Ishiwatari', Naoki Uemura', Toshinori Okuda ${ }^{2}$, Junji Kato ${ }^{1}$}

${ }^{1}$ Departments of Medical Oncology and Hematology, Sapporo Medical University School of Medicine, Sapporo, Japan 2 Departments of Hematology and Oncology, Oji General Hospital, Tomakomai, Japan

\section{References}

1 Barnardo A, Fotiadis N, Meenan J et al. Endoscopic management of intraductal papillary mucinous tumors fistulating into the common bile duct. Gastrointest Endosc 2007; 66: $1060-1062$

2 Patel A, Lambiase L, Decarli A et al. Management of the mucin-filled bile duct: a complication of intraductal papillary mucinous tumor of the pancreas. JOP 2005; 6: 255-259

3 Goto N, Yoshioka M, Hayashi M et al. Intraductal papillary-mucinous neoplasm of the pancreas penetrating to the stomach and the common bile duct. JOP 2012; 13: 61 -65

4 Seynaeve L, Van Steenbergen $W$. Treatment by insertion of multiple uncovered metallic stents, of intraductal papillary mucinous neoplasm of the pancreas with biliary obstruction by mucus impaction. Pancreatology $2007 ; 7: 540-543$

\section{Bibliography}

Dol http://dx.doi.org/

10.1055/s-0034-1377948

Endoscopy 2014; 46: E634-E635

(c) Georg Thieme Verlag KG

Stuttgart · New York

ISSN 0013-726X

\author{
Corresponding author \\ Tsuyoshi Hayashi \\ Departments of Medical Oncology \\ and Hematology \\ Sapporo Medical University School of Medicine \\ South-1, West-16, Chuo-ku \\ Sapporo, Hokkaido 060-8543 \\ Japan \\ Fax: +81-11-612-7987 \\ thayashi69@sapmed.ac.jp
}

